\title{
A Survey of Anti-biotic Usage and its Effects in Port Harcourt City in the Niger Delta of Nigeria
}

\author{
${ }^{1 *}$ SHORINWA, O A; ${ }^{2}$ ENIOJUKAN, J F \\ ${ }^{1}$ Department of Clinical Pharmacy and Management, Faculty of Pharmaceutical Sciences, University of Port Harcourt, Port Harcourt, \\ Rivers State \\ ${ }^{2}$ Department of Clinical Pharmacy and Pharmacy Practice, Faculty of Pharmacy, Niger Delta University, Wilberforce Island, Bayelsa State
}

\begin{abstract}
The pattern of using antibiotics in community pharmacies in Portharcourt city was investigated with a view of measuring the existing practices in the consumer use of antibacterial drugs. This will serve as a guide to health policy makers to improve rational use of drugs. The parameters investigated are the pattern of sale of antibacterial drugs, pharmacist-patient communication at the point of sale, knowledge, attitude and practices of the consumers. The instruments for the research consisted of two sets of questionnaires. Ninety-five questionnaires were distributed to community pharmacists and three hundred and twenty questionnaires were distributed to consumers. The study showed that $36 \%$ of the respondents sold ampiclox and $50 \%$ sold other antibacterial drugs. $13 \%$ of the consumers frequently purchased antibacterial drugs while $80 \%$ of the respondents purchased the drugs occasionally. $63 \%$ of the consumers purchased sub-therapeutic dose of antibacterial drugs while the remaining $37 \%$ purchased standard therapeutic dose. $73 \%$ of the respondents did not indicate their reasons for not accepting the counseling. Meanwhile $8 \%$ refused counseling as a result of their habits and $3 \%$ due to ignorance. The results showed common trend of occasional purchase of optimal dosage of antibacterial drugs. Furthermore, $64 \%$ of the consumers got to know about antibacterial drugs through prescriptions and $82 \%$ of the consumers are aware that inappropriate use of antibacterial drugs can lead to the development of resistance. Drug use is the end of therapeutic consultation. Improving drug use enhances the quality and lowers cost of healthcare. @ JASEM
\end{abstract}

\section{INTRODUCTION}

Antibacterial agents are used in the treatment of communicable and infectious diseases. A substantial proportion of the total budgets in many countries are dedicated to antibacterial drugs and they are often the largest single group of drugs purchased in developing countries. Relatively high levels of availability and consumption of antibacterial drugs in developing countries have led to disproportionately higher incidence of inappropriate use and greater levels of resistance compared to developed countries (WHO, 1988). Among these is the inappropriate use by healthcare providers and consumers with the increase of drug resistance which often leads to failure in therapy.

Surveys on antibiotic use in developing countries show that antibacterial drugs prescribed in $35 \%$ to $60 \%$ of clinical encounters is only appropriate in less than $20 \%$ (Trostle, 1996). It was also reported that dispensing professionals spent less time with their patients in consultation yet prescribed more drugs, more antibacterial drugs and more injections (Trap, 2002, ICIUM 1997) . Antibacterial drugs are overused in self-medication for the treatment of minor disorders such as simple diarrhea, cough and colds, when antibacterial drugs are used too often in sub-optimal dosages, bacteria become resistant to them. These indicate the continuing need to curb the irrational or inappropriate use of antibacterial drugs and to identify effective interventions to improve drug use. There is need for rational use of all drugs.
This study is highly significant as it will serve as a guide to health policy-makers in decision making, strengthen drug regulation and improve rational use of antibacterial drugs in both public and private sectors, and by both health professionals and consumers. This study, therefore, aims to determine the pattern of sale, pharmacist-patient communication at the point of sale, knowledge, attitude and practices of consumers regarding the use of ampicillincloxacillin, ampicilin, tetracycline, metronidazole, trimethoprim-sulphamethoxazole.

\section{MATERIALS AND METHODS}

The instruments for this study consisted of two sets of questionnaires, ninety-five questionnaires for community pharmacists and three hundred and twenty questionnaires distributed to consumers in Portharcourt City, a metropolitan city in the Niger Delta region of Nigeria. The questionnaires covered the demography of respondents, awareness of antibacterial drugs, pattern of purchase, frequency of sale, frequency of communication and counseling. The professional qualifications and the years of experience of the community pharmacists were also considered. Seventy-five questionnaires were correctly filled and returned by the community pharmacists. This represents approximately seventynine percent $(79 \%)$. Three hundred questionnaires were returned by the consumers. This represents approximately ninety-four percent $(94 \%)$. 
Statistical Analysis: All data were entered into a computer using the SPSS version 11 software package. Data analysis was done with the same software package.

\section{RESULTS AND DISCUSSION}

Sex Distribution: Sixty-three percent $(63 \%)$ of the community pharmacists were males and thirty six percent $(36 \%)$ were females while one percent $(1 \%)$ did not indicate their sex. In the consumers' questionnaires, fifty-eight percent $(58 \%)$ of the respondents were males and thirty-nine percent were females. Three percent $(3 \%)$ did not respond to the question.

Location of Pharmacy: It was observed that (91\%) of the pharmaceutical premises were located in the urban area. Pharmacists professional qualification: Seventy-five $(75 \%)$ of the community pharmacists had B-Pharm degree but only one percent $(1 \%)$ had B-Pharm/Msc degrees. Eight percent $(8 \%)$ of them had WAPCP fellowship (FPCPharm) and B-Pharm with Pharm.D degrees. Forty out of the seventy-five respondents had at least ten years of practice. Thirty of the respondents had about twenty years experience but only six had over twenty years of experience. Thirty-six percent $(36 \%)$ of the respondents sold ampiclox and fifty percent (50\%) sold other antibacterial drugs. Only one percent $(1 \%)$ of the respondents indicated that they usually sell

The results obtained from the consumers showed that twenty-seven percent $(27 \%)$ of the respondents purchased ampiclox, eight percent $(8 \%)$ purchase ampicillin while the least purchased drug is tetracycline with a percent of three (3\%) (Fig 1).

Thirteen percent $(13 \%)$ of the consumers frequently purchased antibacterial drugs while eighty percent $(80 \%)$ of the respondents purchased the drugs occasionally and seven percent $(7 \%)$ did not purchase the drugs (Fig 2). Seventy-three percent (73\%) of the consumers completed the dose of antibacterial drugs as prescribed while thirteen percent $(13 \%)$ did not complete the dosage. Sixty-three percent $(63 \%)$ of the consumers purchased sub-therapeutic dose of antibacterial drugs while the remaining thirty-seven percent $(37 \%)$ purchased standard therapeutic dose of the drugs (Fig 3). The counseling done at the point of sale by the pharmacists was occasionally effective. Seventy-seven percent (77\%) of the respondents indicated that they have been counseled by pharmacists while eighteen percent $(18 \%)$ said they have never been counseled. However, five percent (5\%) of the respondents did not respond to the question (Fig 4). Thirty-six percent (36\%) of the pharmacists did not indicate how the consumers responded to counseling. However, thirty-two (32\%) of the consumers were reported to accept counseling while thirty-two percent $(32 \%)$ of the consumers refused counseling and walked away (Fig 5). Seventy-three percent $(73 \%)$ of the respondents did not indicate their reasons for not accepting the counseling. Meanwhile, eight percent $(8 \%)$ refused counseling as a result of their habits and three percent said it was done due to ignorance (Fig 6). Sixty-four percent $(64 \%)$ of the respondents were introduced to antibacterial drugs through prescription while ten percent $(10 \%)$ learnt about them from previous experience, eight percent $(8 \%)$ from friends and neighbours, three percent $(3 \%)$ through family orientation, five percent $(5 \%)$ learnt about it from other sources and ten percent $(10 \%)$ of the respondents did not respond to the question (Fig 7).

Eighty-one percent $(81 \%)$ of the respondents were aware that inappropriate use of antibacterial drugs could lead to the development of resistance (Fig 8). Forty-six percent (46\%) of the respondents believed that antibacterial drugs are used for the prevention of infections. Majority of the university graduates often purchased optimal dosage of antibacterial drugs. Very few undergraduates and primary school certificate holders responded to the questionnaire. All the respondents that had income from thirty thousand naira $(\$ 30,000)$ to ninety thousand naira $(\$ 90,000)$ per month purchased optimal dosage, but consumers with income from ninety thousand naira $(\$ 90,000)$ to one hundred and twenty thousand naira $(\$ 120,000)$ did not purchase optimal dosage. Irrespective of their ages, the results showed common trend of occasional purchase of optimal dosage of antibacterial drugs.

From the results, it was evident that there is a high level of consumer awareness on the use of antibacterial drugs. This is because $46 \%$ of the respondents believed that antibacterial drugs are used for the prevention of infections which accounts for their indiscriminate purchase and use by the public. Ampiclox (Ampicillin-cloxacillin) was the most frequently purchased antibacterial drug while the least purchased is tetracycline. The findings revealed that $80 \%$ of the respondents purchased the drugs occasionally while $7 \%$ did not purchase the drugs at all.

This also showed the level of awareness of the consumers on the use of antibacterial drugs. The results also showed that a high percentage $(63 \%)$ of the consumers purchase sub-therapeutic doses of the antibacterial drugs while $37 \%$ purchased standard therapeutic dose. 


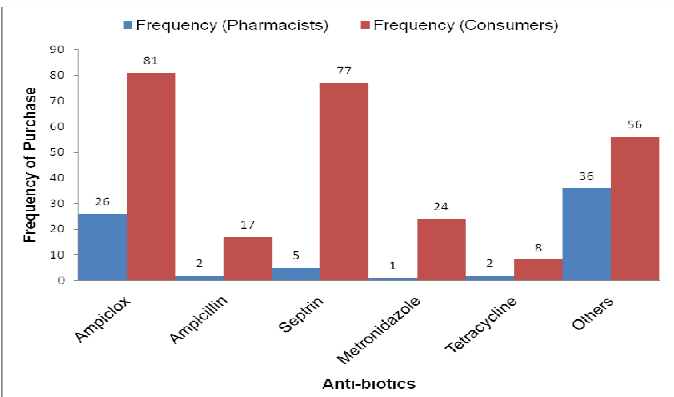

Fig 1. Pattern of purchase of antibacterial drugs (Pharmacists \& Consumers)

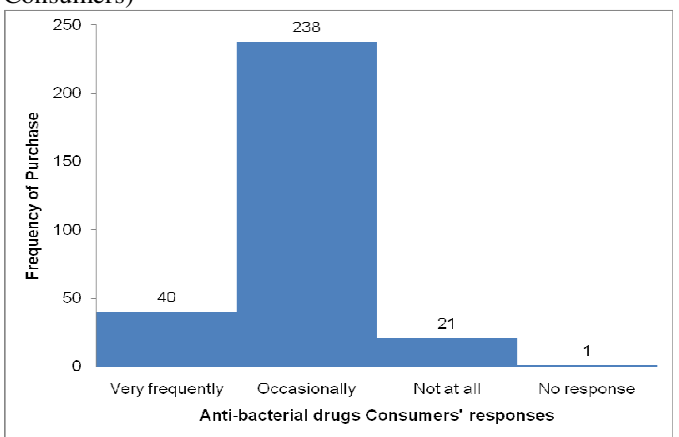

Fig 2. Frequency of purchase of anti-bacterial drug

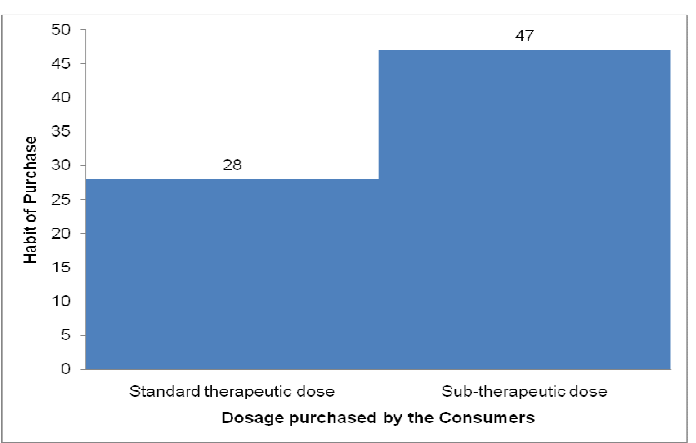

Fig 3. Habit of purchase of the consumers.

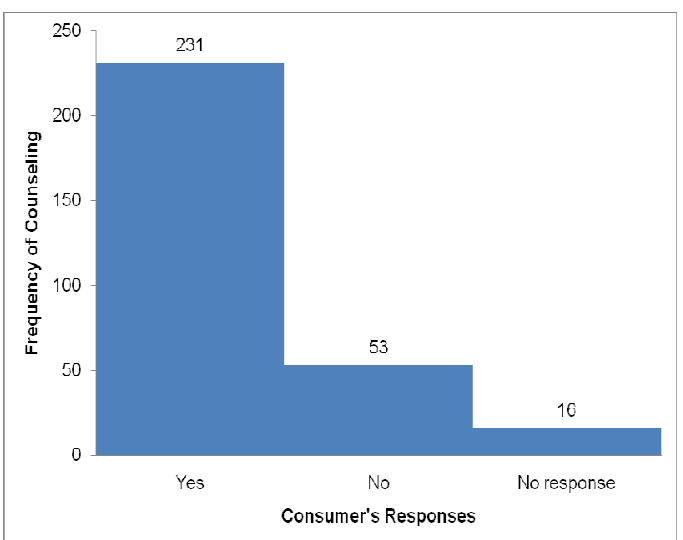

Fig 4. Frequency of Pharmacists' counsel to consumers

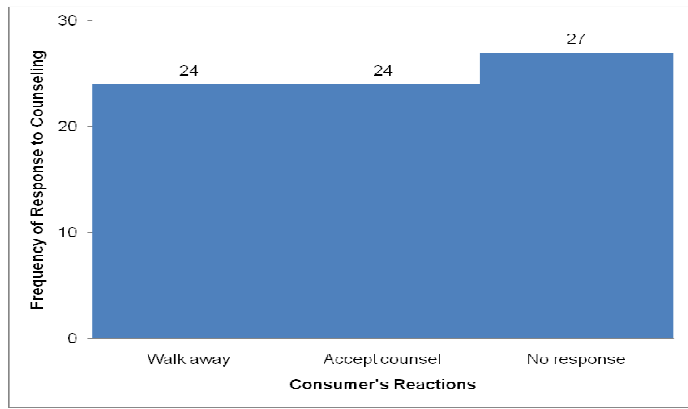

Fig 5. Consumers' reactions to Pharmacists' counsel

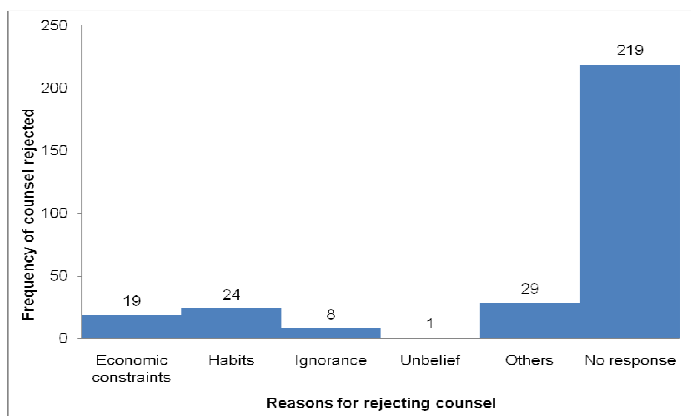

Fig 6. Consumers' reasons for rejecting Pharmacists' counsel.

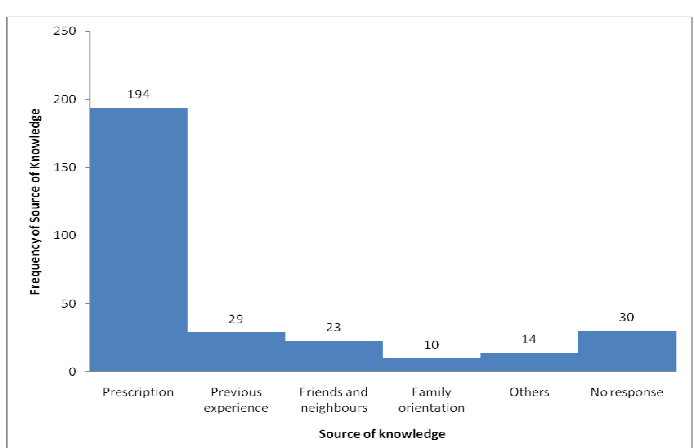

Fig 7. Consumers' source of knowledge of anti-bacterial drugs.

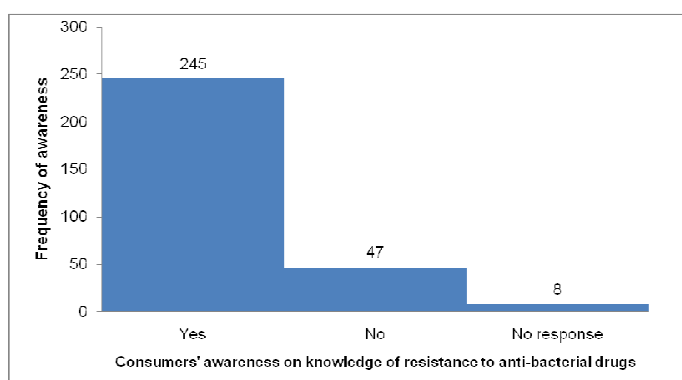

Fig 8. Consumers' awareness on knowledge of resistance to antibacterial drugs

This shows the level of misuse of antibacterial drugs. However when antibacterial drug is prescribed, seventythree percent of the consumers completed the dose. All the 
respondents that had income from thirty thousand naira to ninety thousand per month purchased optimal dosage, but consumers with income from ninety thousand naira to one hundred and twenty thousand naira were not often purchasing optimal dosage. This further shows that the purchase of optimal dosage is independent of the consumer's income. Approximately eighty-two percent $(82 \%)$ of the consumers were aware that inappropriate use of antibacterial drugs can lead to the development of resistance to the drug.

These findings correspond with the estimation of World Health Organisation (WHO) that more than half of all medicines were prescribed, dispensed or sold inappropriately, and that half of all patients failed to take them correctly. People who have not understood the need to complete the course stop using antibacterial drugs when the symptoms disappear. Others take overdose as they think that this will lead to faster recovery (Hardon et al1993). The overuse, underuse, or misuse of medicines results in wastage of scarce resources and widespread hazards. Results shown in Figures 5 and 6 indicated the frequency of counseling done by the pharmacists and the reasons the consumers did not accept the counseling. Some of the consumers did not indicate their reasons for not accepting the counseling while $8 \%$ refused counseling as a result of their habits. Thirty- two percent $(32 \%)$ of the consumers were reported to accept counseling while thirty- two percent $(32 \%)$ refused counseling and walked away. Also, from the research findings, it was discovered that the counseling done by the pharmacists were occasionally effective irrespective of the years of their experiences. This corresponded with the reports of Greenhalgh (1993) that consumers engage in self-initiated therapy with drugs left over from previous treatment. Most of the consumers that purchased optimal dosage were highly educated with University degree, but respondents with low levels of education did not respond to this questionnaire appropriately. Forty-six percent of the consumers believed that antibacterial drugs are used for disease prevention. It was also observed that majority of the consumers got to know about antibacterial drugs through previous prescriptions and peers, but only became familiar with the name but not the optimal dosage. This corresponds with the observation of Lansang et al $(1990,1991)$ which reported that $57 \%$ of 6404 antibiotic prescriptions were without a prescription.

Conclusion: Most consumers in this city are aware that inappropriate use of antibacterial drugs can lead to the development of bacterial resistance and adverse drug reactions. Yet a sizeable number of them still go ahead to purchase sub-optimal dosages. Irrespective of their ages and income the results showed a common trend of occasional purchase of optimal dosage of antibacterial drugs. The counseling done at the point of sale by the pharmacists was found to be occasionally effective.
Ampiclox was found to be the most frequently purchased antibacterial drug. It will be necessary to find out what dose of ampiclox is usually purchased by consumers and the resistance pattern. There is need for urgent measures to stem this trend. This can be achieved by promoting rational use of antibacterial drugs. Drug use is the end of therapeutic consultation. Improving drug use improves the quality of care and frequently lower cost of health care. Definite antibacterial policies must be established to prevent the great ease of procuring some antibacterial drugs without prescription from unqualified medical personnel. Effective public education should be carried out. This will provide the consumer with a better understanding of the benefits and the potential dangers of drug use. This could also give a better knowledge of safe sources of drug supply and information. An informed and empowered consumer is able to act on his or her own and the community's best interests. Therefore effective communication should be promoted between pharmacists and consumers.

\section{REFERENCES}

Greenhalgh T.(1987) Drug prescription and self medication in India, an exploratory survey.Social Science and Medicine:25(3);307-318

Hardon.A and Le Grand A (1993)Pharmaceuticals in communities. Practices,public health consequences and intervention strategies. Bulletin 330 Amsterdam,Royal Tropical Institute.

International Conference on Improving the use of Medicines (ICIUM) conference summary 1997.(http://www.who.ch/programmes/dap/icium/sum mary.html).

Lansang M.A, Lucas-Aquino R, Tupasi T.E, Mina V.S, Salazar L.S ,Juban $\mathrm{N}$ and Limjoco T.T (1990).Purchase of antibiotics without prescription in Manilla, The Phillipines: Inappropriate choices and doses. Journal of Clinical Epidemiology,43(1) 61-67.

Lansang M.A ,Aquino R.L,Tupasi T.E,Mina V.S,Salazar L.S and Juban N (1991). A drugstore survey of antibiotic use in a rural community in the Phillipines.Phillipines Journal of Microbiology and Infectious diseases.

Trap B.(2002), Prescription habits of dispensing and non dispensing doctors in Zimbabwe, Health Policy and Planning Oxford University Press: 17 (3): 288-295.

Trostle J (1996). Inappropriate distribution of medicine by professionals in developing countries.Social Science and Medicine;42(8) 1117-1120.

World Health Organization (1988).The World Drug Situation. Geneva. 